\title{
Iodinated Contrast Agents Perturb Iodide Uptake by the Thyroid Independently of Free Iodide
}

\author{
Georges Vassaux ${ }^{1,2}$, Colette Zwarthoed ${ }^{1-3}$, Laurie Signetti ${ }^{1,2}$, Julien Guglielmi ${ }^{1,2}$, Catherine Compin ${ }^{1,2}$, \\ Jean-Marie Guigonis ${ }^{1,2,4}$, Thierry Juhel ${ }^{2,5}$, Olivier Humbert ${ }^{1-3}$, Danielle Benisvy ${ }^{3}$, Thierry Pourcher ${ }^{1,2}$, \\ and Béatrice Cambien ${ }^{1,2}$
}

${ }^{1}$ Laboratoire TIRO, UMRE 4320, CEA, Nice, France; ${ }^{2}$ Université de Nice-Sophia Antipolis, Nice, France; ${ }^{3}$ Centre Antoine Lacassagne, Department of Nuclear Medicine, Nice, France; ${ }^{4}$ Plateforme "Bernard Rossi," Faculté de Médecine, Université de Nice Sophia Antipolis, Nice, France; and ${ }^{5}$ Institute for Research on Cancer and Aging (IRCAN U1081; UMR CNRS 7284), Nice, France

Perturbation of thyroid iodide uptake is a well-documented side effect of the use of iodinated contrast media (ICM) administered intravenously. This side effect is thought to be mediated by free iodide in ICM formulations, but this hypothesis has never been formally proven. The aim of the present study was to assess the validity of this hypothesis. Methods: We used mass spectrometry analysis to quantify free-iodide contamination in ICM. Established cell lines expressing the $\mathrm{Na} / \mathrm{l}$ symporter (NIS) were used to quantify the effect of ICM on iodide uptake. SPECT/CT was used to measure the in vivo uptake of ${ }^{99 m T c-p e r t e c h n e t a t e ~ a n d ~}{ }^{123} \mathrm{I}$ in 2 NIS-expressing mouse tissues, thyroid and salivary glands. Scintiscans of ICM-naïve and ICMadministered patients were compared. Immunohistologic and Western blot analyses were performed to evaluate NIS protein expression in these organs. Results: Although free iodide was present in ICM formulations, in vitro uptake of iodide by NIS-expressing cells was not significantly affected by ICM. In mice, intravenous or sublingual administration of ICM led to a reduction in radiotracer uptake by the thyroid, accompanied by a dramatic reduction in NIS protein expression in this tissue. In the salivary glands, neither radiotracer uptake nor NIS protein expression was affected by ICM. The thyroid-selective effect of ICM was also observed in humans. Administration of potassium iodide as a source of free iodide led to a diminution of ${ }^{99 m T c-}$ pertechnetate uptake in both mouse thyroid and mouse salivary glands. Altogether, these data rule out a direct intervention of free iodide in the perturbation of thyroid uptake and suggest a direct and selective effect of ICM on the thyroid. Conclusion: We demonstrated that ICM reduce thyroid uptake of iodide independently of free iodide. This effect is due to a specific and dramatic decrease in NIS expression in thyrocytes. These data cast serious doubt on the relevance of measuring urinary iodide concentration to evaluate the delay between ICM administration and radioiodine therapy in patients with differentiated thyroid carcinoma. Finally, the ability of ICM to perturb iodide uptake in the thyroid may be used in radioprotection.

Key Words: iodide uptake; thyroid; salivary glands; iodinated contrast media; free iodide

J Nucl Med 2018; 59:121-126

DOI: 10.2967/jnumed.117.195685

\footnotetext{
Received May 4, 2017; revision accepted Aug. 1, 2017.

For correspondence or reprints contact: Georges Vassaux, Université de Nice-Sophia Antipolis, Laboratoire TIRO, 28 Avenue Valombrose, Nice 06107, France.

E-mail:vassaux@unice.fr

Published online Oct. 19, 2017.

COPYRIGHT @ 2018 by the Society of Nuclear Medicine and Molecular Imaging.
}

I odinated contrast media (ICM) are routinely administered to patients for $x$-ray imaging. In view of their widespread use, they can be considered safe. However, a well-documented side effect of intravenous ICM administration observed in most patients is compromise of diagnostic thyroid scintigraphy and radioiodine treatment of thyroid malignancies (1-5). For the latter, guidelines recommend delaying radioactive iodide treatment in patients who have been exposed to ICM $(4,6-8)$. Mechanistically, this reduced iodide uptake by thyroid tissues in response to ICM is thought to be the result of injection of high amounts of free iodide contaminating the ICM formulation (9). Many studies have reported that urinary iodide concentration remains high for days or even weeks after ICM administration $(10,11)$. This high urinary iodide concentration may reflect a high blood iodide content that could be consistent with the long-lasting effect of ICM on thyroid iodide uptake. The source of this free iodide may be free iodide associated with ICM (9) or free iodide released from ICM on injection $(4,12)$. However, although this hypothesis is generally accepted, it has never, to our knowledge, been formally proven.

The protein responsible for iodide uptake is $\mathrm{Na} / \mathrm{I}$ symporter (NIS), which is located at the basolateral membrane of some epithelial cells, including thyrocytes in the thyroid $(13,14)$ and duct cells in the salivary gland (15). Ingestion of a large amount of potassium iodide (KI) leads to a high blood iodide content, which in turn dramatically reduces uptake of radioiodide and its surrogate, ${ }^{99 \mathrm{~m}} \mathrm{Tc}$-pertechnetate $\left({ }^{99} \mathrm{~m} \mathrm{TcO}_{4}{ }^{-}\right)$, in the thyroid and the salivary glands (16). However, this effect is transient, and a return to normal uptake capacities for both tissues is observed within $24 \mathrm{~h}$ after a single administration of a large amount of KI.

In this context, the aim of the present study was to determine experimentally whether the free iodide that contaminates ICM (9) or that can be released in vivo through deiodination of ICM in tissues $(4,12)$ is responsible for the reduced iodide uptake by thyroid tissues. If either or both of these hypotheses are correct, Iomeron (Bracco Imaging) (as a prototype of ICM) would be expected to act in the same way as free iodide on iodide uptake in NIS-expressing cells and tissues.

\section{MATERIALS AND METHODS}

\section{Animals}

Eight-week-old female C57BL/6JRj mice were obtained from Janvier. The animals were treated in accordance with the French Agriculture Ministry guidelines, and the experiments were approved 
by the University of Nice Sophia Antipolis Animal Care User and Ethics Committee (Ciepal NCE/2014-211).

\section{Contrast Agents}

Experiments were performed using iomeprol (Iomeron 350; lot LP4557) and iodixanol (Visipaque 320 [GE Healthcare]; lot 12578 776).

\section{Cell Lines}

The human colorectal cancer cell line HT-29 (HTB-38; American Tissue Culture Collection) was stably transfected with the expression plasmid pcDNA3.1-mNIS (murine NIS) (17), and a single clone with high functional expression of NIS was selected (18). The rat follicular thyroid cell line PCCL3 was obtained from Dr. Antonio De La Vieja (Madrid, Spain) and cultured as previously described (19). In vitro iodide uptake was measured as previously described (20).

\section{Mass Spectrometry}

Iomeron, Visipaque, and standard solutions of $\mathrm{NaI}$ were characterized by high-resolution mass spectroscopy in negative-mode electrospray. For the direct-infusion experiments, a flow of $5 \mu \mathrm{L} / \mathrm{min}$ was provided by a syringe pump (11 Plus; Harvard Apparatus) using a $500 \mu \mathrm{L} / \mathrm{min}$ syringe (Hamilton). The mass spectrometer (Q Exactive Plus; Thermo Fisher Scientific) was operated with an electrospray source for the direct-infusion method. The direct-infusion Orbitrap measurements were performed using the Ion Max source from Thermo Fisher Scientific and applying the following parameters: sheath gas flow, 15 arbitrary units; auxiliary gas flow, 5 arbitrary units; and capillary temperature, $275^{\circ} \mathrm{C}$. The automatic gain control target was set to $10^{6}$, and the maximum injection time was $50 \mathrm{~ms}$. In the high-resolution measurements with a setting of 140,000 at $\mathrm{m} / \mathrm{z} 200$, 1 microscan was recorded. The spray voltage in negative mode was selected to be $-2.5 \mathrm{kV}$.

\section{In Vivo Administration of ICM to Mice}

Intravenous and intraperitoneal administration was performed by injecting $100 \mu \mathrm{L}$ of Iomeron diluted 50/50 (v/v) with phosphate-buffered saline (corresponding to $18 \mathrm{mg}$ of iomeprol). Enteral administration was performed by gavage of $100 \mu \mathrm{L}$ of Iomeron diluted $50 / 50(\mathrm{v} / \mathrm{v})$ with phosphate-buffered saline (corresponding to $18 \mathrm{mg}$ of iomeprol). Sublingual administration was performed on anesthetized mice by 5 sublingual depositions of $5 \mu \mathrm{L}$ of Iomeron, with a delay of $10 \mathrm{~min}$ in between. This procedure led to the administration of $9 \mathrm{mg}$ of iomeprol.

\section{Small-Animal SPECT/CT}

${ }^{99} \mathrm{TcO}_{4}{ }^{-}$was obtained from a freshly eluted ${ }^{99} \mathrm{Mo} /{ }^{99 m} \mathrm{Tc}$ generator. ${ }^{123} \mathrm{I}-\mathrm{NaI}$ was purchased from IBA. The animals received $20 \mathrm{MBq}$ of ${ }^{99} \mathrm{mcO}_{4}{ }^{-}$or $10 \mathrm{MBq}$ of ${ }^{123} \mathrm{I}^{-}$intraperitoneally. Thyroid and salivary gland uptake was measured at different times using a dedicated smallanimal SPECT/CT scanner (eXplore speCZT CT120; GE Healthcare) as previously described (21). Reconstructed images were analyzed and quantified using AMIDE software (22). Tridimensional regions of interest were drawn manually around the thyroid and salivary glands as previously detailed $(23,24)$. Uptake was expressed as percentage injected activity after decay correction (21).

\section{Kinetics of ${ }^{99} \mathrm{TcO}_{4}{ }^{-}$or ${ }^{123} \mathrm{I}-\mathrm{Nal}$ Uptake Inhibition by ICM and $\mathbf{K I}$}

For ICM inhibition of ${ }^{99} \mathrm{TcO}_{4}{ }^{-}$or ${ }^{123} \mathrm{I}-\mathrm{NaI}$ uptake, SPECT/CT

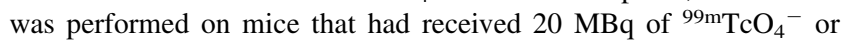
$10 \mathrm{MBq}$ of ${ }^{123} \mathrm{I}-\mathrm{NaI}$ (basal uptake, day 0). At the end of the scan, ICM was administered. At different times after ICM administration, the animals were injected with $20 \mathrm{MBq}$ of $99 \mathrm{~m} \mathrm{TcO}_{4}{ }^{-}$or $10 \mathrm{MBq}$ of ${ }^{123} \mathrm{I}-\mathrm{NaI}$ and new scans were obtained.

For KI inhibition of ${ }^{99} \mathrm{mcO}_{4}{ }^{-}$uptake, SPECT/CT was performed on mice that had received $20 \mathrm{MBq}$ of ${ }^{99} \mathrm{TcO}_{4}{ }^{-}$(basal uptake).
Twenty-four hours later, the animals were injected intraperitoneally with $\mathrm{KI}(9 \mathrm{mg}$ in $180 \mu \mathrm{L})$. The animals were then injected $30 \mathrm{~min}$ later with $20 \mathrm{MBq}$ of ${ }^{99} \mathrm{mcO}_{4}{ }^{-}$and scanned. Twenty-four hours later, the animals were injected with $20 \mathrm{MBq}$ of ${ }^{99} \mathrm{TcO}_{4}{ }^{-}$and new scans were obtained.

\section{Thyroid and Salivary Gland Uptake of ${ }^{99 \mathrm{~m} \mathrm{TcO}_{4}}{ }^{-}$in Humans}

An ICM-naïve patient and a patient who had received an intravenous injection of Iomeron $3502 \mathrm{wk}$ before scintigraphy were chosen for study. On the day of the scintigraphy, the patients were injected intravenously with a $1 \mathrm{MBq} / \mathrm{kg}$ activity and 600-s scans were obtained 15 min later. The institutional review board approved this retrospective study, and the anonymized scans were obtained as part of routine medical examinations with consent of the patients.

\section{Immunohistochemistry and Western Blot Analyses}

After animals had been killed, the thyroids and salivary glands were dissected. Some thyroids and salivary glands were paraffin-embedded and cut into $4-\mu \mathrm{m}$-thick sections. The paraffin was then removed and the sections were rehydrated and subjected to an antigen retrieval treatment with a solution of citrate buffer, $\mathrm{pH} 6$, using an automated station (PT Link; Dako). NIS immunostaining was performed as previously described (21). For Western blot analysis, thyroid and salivary gland membrane proteins were subjected to electrophoresis as previously described (21). Western blot analysis was performed with antibody 25 antimouse NIS, an affinity-purified rabbit immunoreactive serum fraction, or an anti- $\beta$-actin antibody (Sigma).

\section{Statistical Analysis}

Statistical analysis was performed using Prism (GraphPad Software). Dual comparisons were made using a Student $t$ test, and comparisons between multiple conditions were analyzed using ANOVA. Statistical significance was set at a $P$ value of less than 0.05 .

\section{RESULTS}

\section{Free lodide Content of ICM}

We first evaluated whether free iodide was present in commercially available ICM. Mass spectrometry analysis revealed that the concentrations of free iodide in Iomeron and Visipaque were in the range of 30 and $100 \mu \mathrm{M}$, respectively. The details of this dataset are available in Supplemental Figure 1 (supplemental materials are available at http://jnm.snmjournals.org).

\section{Effect of ICM on Uptake of lodide in Cell Lines}

We next examined whether iomeprol and its contaminating free iodide could affect iodide uptake in NIS-expressing cell lines. PCCL3 cells (a rat follicular thyroid cell line) were incubated with ${ }^{125} \mathrm{I}$ in the presence of either saline buffer, Iomeron, $\mathrm{NaI}$, or perchlorate $\left(\mathrm{NaClO}_{4}\right)$. After $1 \mathrm{~h}$, the cells were washed and the cellular ${ }^{125} \mathrm{I}$ content was determined. As expected, both $\mathrm{NaI}$ and perchlorate inhibited iodide uptake in PCCL3 cells, but Iomeron failed to affect this uptake significantly (Fig. 1). Similar data were obtained using the HT29-NIS cell line (a human colorectal carcinoma cell line expressing NIS) (Supplemental Fig. 2).

\section{Effect of ICM on ${ }^{99 m} \mathrm{TcO}_{4}{ }^{-}$Uptake in Mice and Humans}

We evaluated whether Iomeron could affect uptake of the iodide analog, ${ }^{99} \mathrm{mcO}_{4}{ }^{-}$, by the mouse thyroid and salivary glands. Basal uptake was measured before (T0) and after intravenous administration of Iomeron. Figure $2 \mathrm{~A}$ shows that a dramatic reduction in radiotracer uptake by the thyroid was observed $24 \mathrm{~h}$ after Iomeron administration. This uptake capacity remained low 


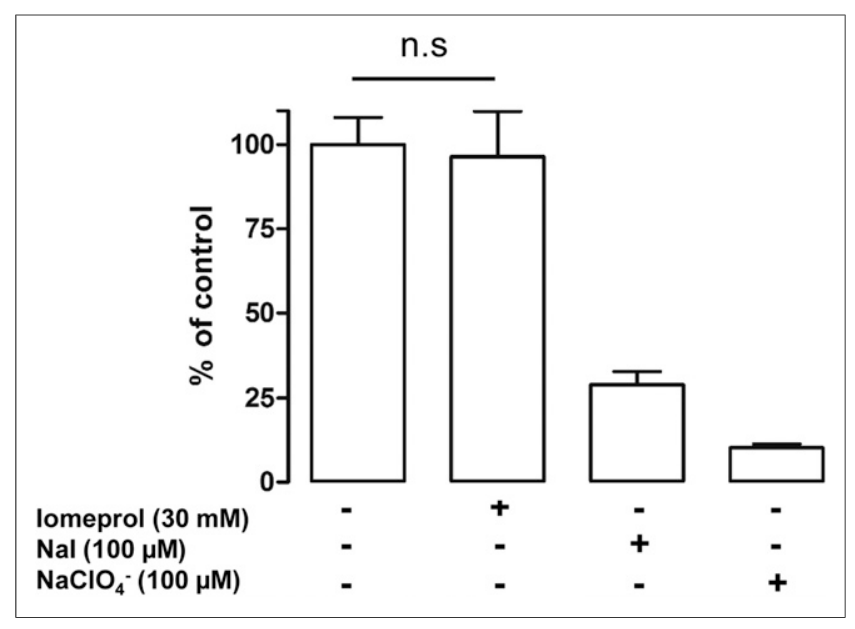

FIGURE 1. Effect of lomeron on iodide uptake of PCCL3 cells. PCCL3 cells were incubated for $1 \mathrm{~h}$ with ${ }^{125} \mathrm{I}$ in equal volume of either saline, lomeron (100 $\mu \mathrm{L}$, corresponding to $71.4 \mathrm{mg}$ of iomeprol in $3 \mathrm{~mL}$ of medium), Nal, or perchlorate. Cells were then rapidly washed with saline buffer and lysed. Aliquots of lysates were counted in y-counter. Results are expressed as percentage uptake under control condition. Data are mean \pm SEM of triplicates and are representative of 3 independent experiments. n.s $=$ not statistically significant.

for $8 \mathrm{~d}$, and a recovery was observed on day 12 . In the same animals, Iomeron administration failed to affect iodide uptake by another NIS-expressing tissue, the salivary glands (Fig. 2B). This differential effect was also obtained when ${ }^{123} \mathrm{I}$ was used as the radiotracer (Supplemental Fig. 3). The differential uptake of ${ }^{99} \mathrm{~m} \mathrm{TcO}_{4}{ }^{-}$by the thyroid and salivary glands was also observed using Visipaque (Supplemental Fig. 4). This observation suggests that ICM affect the mouse thyroid and the salivary glands differently. To evaluate whether this differential action is observed in humans, we compared ${ }^{99} \mathrm{TcO}_{4}{ }^{-}$uptake in the thyroid and salivary glands of an ICM-naïve patient (Fig. 3A) and a patient who had received an intravenous injection of Iomeron $2 \mathrm{wk}$ before (Fig. 3B). Figure $3 \mathrm{~A}$ shows the scintiscan of an ICM-naïve patient in whom both the thyroid and the salivary glands are taking up ${ }^{99} \mathrm{mcO}_{4}{ }^{-}$. The scintiscan of a patient treated with Iomeron shows radiotracer uptake in the salivary glands and a lack of fixation in the thyroid region (Fig. 3B).

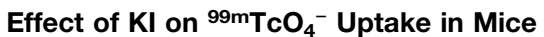

A similar experiment was performed to evaluate the effect of KI on radiotracer uptake by the thyroid and salivary glands. Figure $4 \mathrm{~A}$ shows that the ability of the thyroid to take up ${ }^{99} \mathrm{mcO}_{4}{ }^{-}$was reduced $30 \mathrm{~min}$ after intraperitoneal injection of KI. This capacity was recovered $24 \mathrm{~h}$ after injection. A similar pattern was observed when pertechnetate uptake to the salivary glands was measured (Fig. 4B). This dataset demonstrates that KI affects both thyroidal and salivary gland pertechnetate uptake.

\section{Effect of ICM on NIS Expression in Vivo}

We next evaluated the effect of Iomeron on NIS expression in the thyroid and salivary glands. Immunohistologic analysis revealed that NIS expression was hardly detectable in the thyroid $4 \mathrm{~d}$ after Iomeron injection (Fig. 5B), as compared with control mice (Fig. 5A). By contrast, NIS expression was detectable in the ductal cells of the salivary glands of both control and Iomeron-treated mice (Figs. 5C and 5D). Semiquantitative Western blot analysis confirmed a dramatic decrease in NIS expression in the thyroid glands of Iomeron-treated mice compared with controls (Fig. 5E). No significant difference in NIS expression in the salivary gland was detected between the 2 groups.

\section{Modes of Administration of ICM in Mice}

We next compared the efficacy of different modes of administration of Iomeron on ${ }^{99} \mathrm{mcO}_{4}{ }^{-}$uptake by the thyroid and the salivary glands. Figure 6A shows that intravenous and sublingual administration of the ICM resulted in a marked reduction in radiotracer uptake (Fig. 6A). A similar effect was obtained with Visipaque (Supplemental Fig. 4A), whereas neither enteral nor intraperitoneal administration affected radiotracer uptake by the thyroid. Uptake to the salivary glands was not affected under any condition (Fig. 6B and Supplemental Fig. 4).

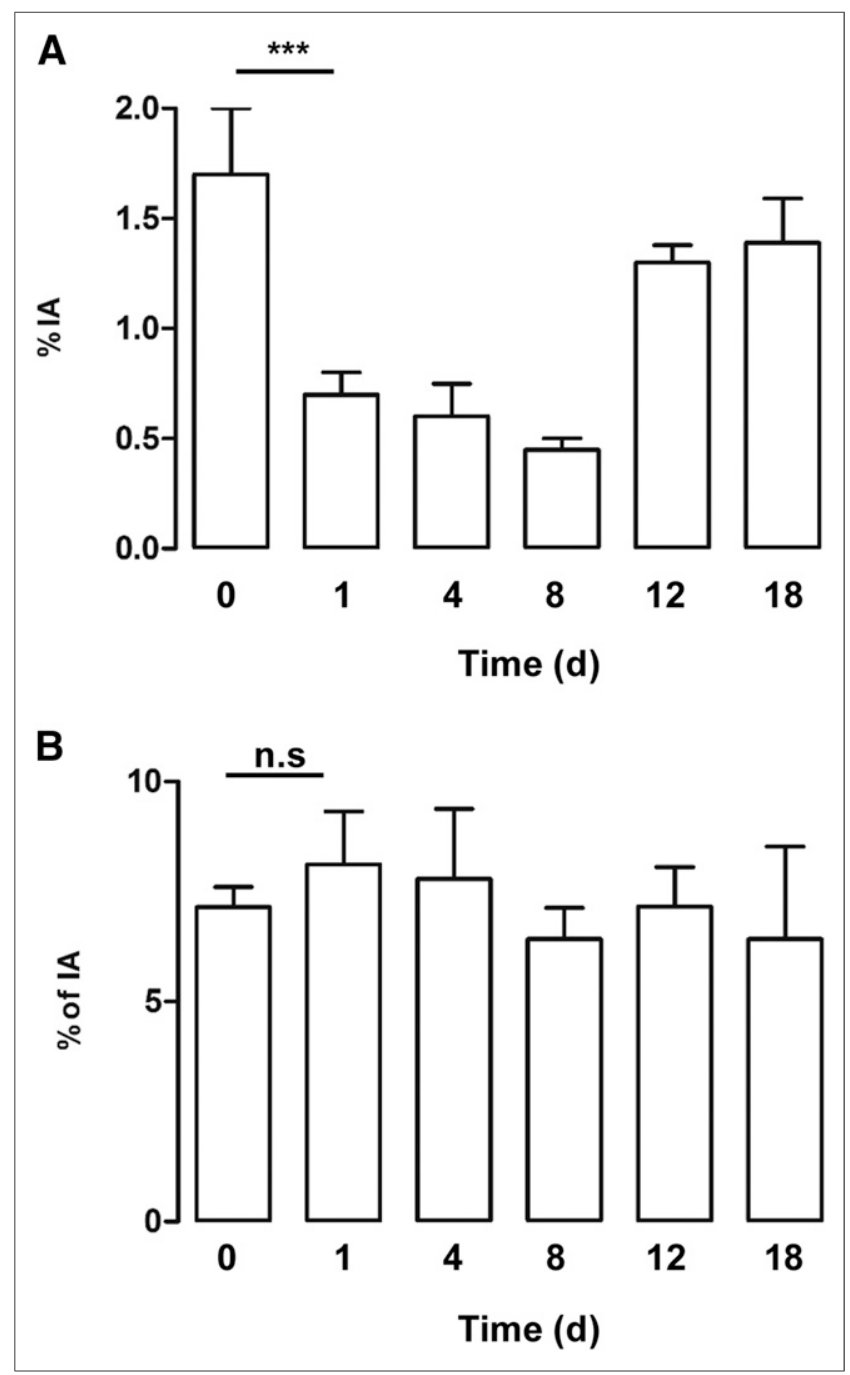

FIGURE 2. Effect of lomeron on uptake of ${ }^{99 \mathrm{~m}_{\mathrm{TCO}}}{ }_{4}^{-}$by mouse thyroid and salivary glands. SPECT/CT of mice given $20 \mathrm{MBq}$ of $99 \mathrm{mTcO}_{4}{ }^{-}$was performed. At end of scan, lomeron was administered intravenously. One, 4, 8, 12, and $18 \mathrm{~d}$ later, animals were injected with $20 \mathrm{MBq}$ of ${ }^{99 m} \mathrm{TcO}_{4}{ }^{-}$and new scans were obtained. Data are percentage radiotracer taken up by thyroid (A) and salivary glands (B) $(n=3$ per condition). ${ }^{* \star} P<0.001$. $\% \mathrm{IA}=$ percentage injected activity; n.s $=$ not statistically significant. 


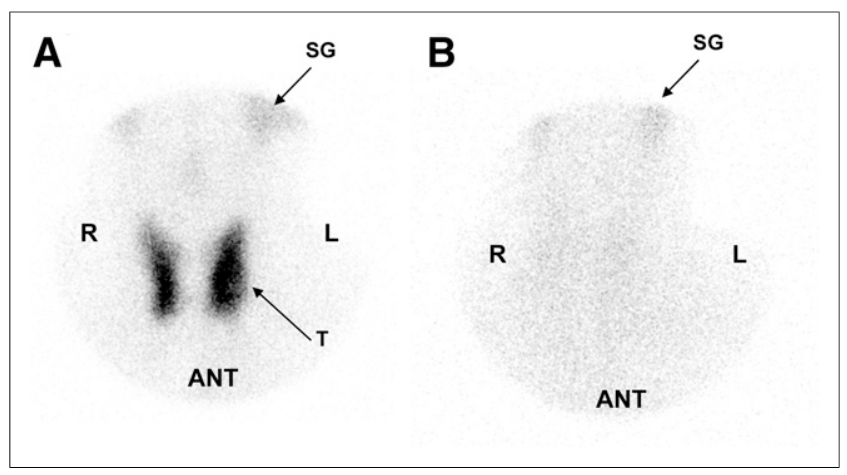

FIGURE 3. Effect of lomeron on uptake of ${ }^{99 \mathrm{~m}_{\mathrm{TcO}}}{ }_{4}^{-}$by human thyroid and salivary glands. Scintiscans are of ICM-naïve patient (A) and patient given lomeron 2 wk before scintigraphy (B). ANT = anterior; $S G=$ salivary glands; $\mathrm{T}=$ thyroid.

\section{DISCUSSION}

Although rare, side effects of the use of ICM, such as thyrotoxicosis, hyperthyroidism, and hypothyroidism, have been reported, both in populations at risk and in some cases in individuals without previous thyroid dysfunction $(4,25,26)$. However, the main side effect observed is the perturbation of iodide uptake by the thyroid. This effect does not appear to affect total intrathyroidal iodine concentration (27). This perturbation has been attributed to the free iodide associated with or released from ICM on administration. We first determined whether free iodide contamination associated with the ICM could mediate this effect. Mass spectrometric analysis was used to quantify the free iodide in Iomeron ( 25 to $30 \mu \mathrm{M}$ free iodide) and Visipaque (100 $\mu \mathrm{M}$ free iodide). In addition, competition experiments using NIS-expressing cells demonstrated that Iomeron did not affect iodide uptake. These in vitro results suggest that if free iodide is involved in the perturbation of iodide uptake by the thyroid in vivo, it must be released in the body from the deiodination of ICM in tissues that may store ICM. The possibility of such ICM deiodination has been demonstrated $(4,12)$, and considering the high amount of iodide associated with the organic backbone of the ICM, deiodination may be the source of a delayed release of iodide to the circulation sufficient to perturb thyroid uptake.

Free iodide perturbed uptake of the iodide analog, ${ }^{99} \mathrm{mcO}_{4}{ }^{-}$, by both mouse thyroid and mouse salivary glands. Kinetically, for both organs, uptake decreased rapidly (30 min after KI injection in our experiment), and the capacity of the thyroid to take up the radiotracer was restored within $24 \mathrm{~h}$. In comparison, iomeprol affected uptake of ${ }^{99} \mathrm{~m} \mathrm{TcO}_{4}{ }^{-}$to mouse thyroid selectively. As expected from the well-known biodistribution of these 2 radiotracers (28), this effect was also observed with ${ }^{123}$ I. Figure 3 represents 2 scintiscans obtained from human patients. These human data are consistent with the animal results. However, considering the small number of cases, this dataset can be taken as only an indication rather than a formal demonstration of a differential uptake of ${ }^{99} \mathrm{TcO}_{4}{ }^{-}$by the thyroid and salivary glands on ICM administration. Nevertheless, overall, our data rule out a direct intervention of free iodide in the perturbation of uptake to the thyroid and suggest a direct and selective effect of iomeprol on the thyroid. Considering that similar data were obtained with Visipaque, it is tempting to hypothesize that ICM, in general, act directly and selectively on the thyroid.

In patients, urinary iodide content has been shown to be elevated for several weeks after ICM injection, and a 4- to-6-wk period is considered necessary for urinary iodide to return to normal levels $(10,11,29,30)$. These observations provide the basis for the advised 4- to 6-wk delay between ICM injection and radioiodine therapy in thyroid cancer patients (7). This implies that urinary iodide has been used as a surrogate marker of the restoration of normal iodide uptake by thyroid tissues. Our results cast serious doubt on the relevance and usefulness of the measurement of urinary iodide concentration in the context of ICM and radioiodine therapy. In our experimental conditions, in mice, the ICMmediated thyroid stunning lasted for at least $8 \mathrm{~d}$ and a recovery was observed by day 12 . These data are consistent with a longlasting effect of a single injection of ICM in humans. The recommended delay between ICM injection and radioiodine therapy is currently between 4 and $8 \mathrm{wk}$. If the recommended delay between ICM injection and radioiodine therapy were to be reduced or optimized, we advocate that dedicated trials should be performed and based on functional imaging of the thyroid.

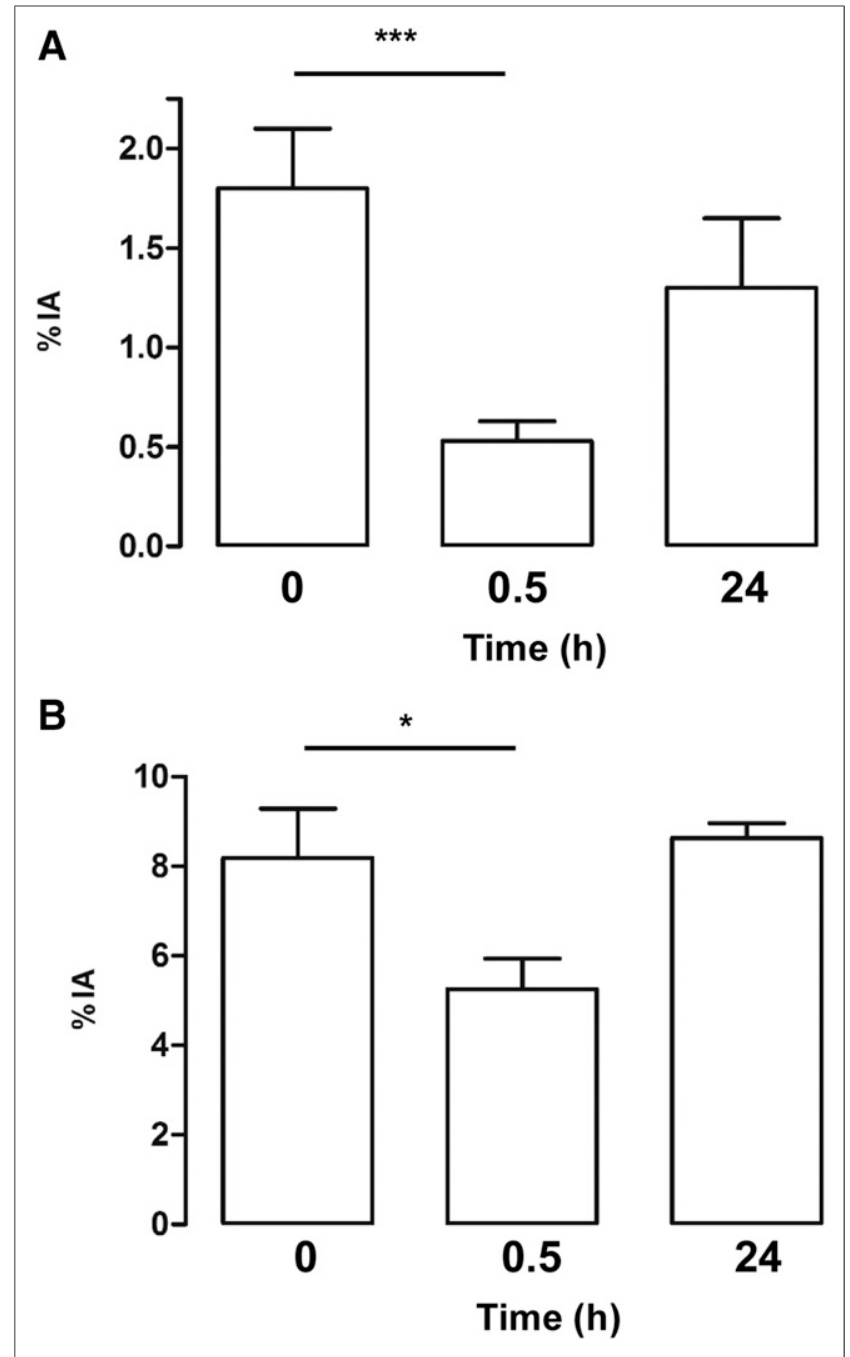

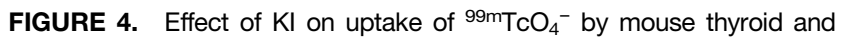

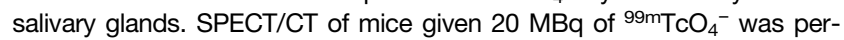
formed. Animals were injected intraperitoneally with $\mathrm{KI}(9 \mathrm{mg}$ in $180 \mu \mathrm{L})$ and scanned 30 min later. Twenty-four hours later, animals were injected with

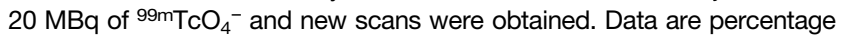
radiotracer taken up by thyroid (A) and salivary glands (B) $(n=3$ per condition). ${ }^{\star} P<0.05$. ${ }^{\star \star \star} P<0.001$. \% $\mathrm{IA}=$ percentage injected activity. 


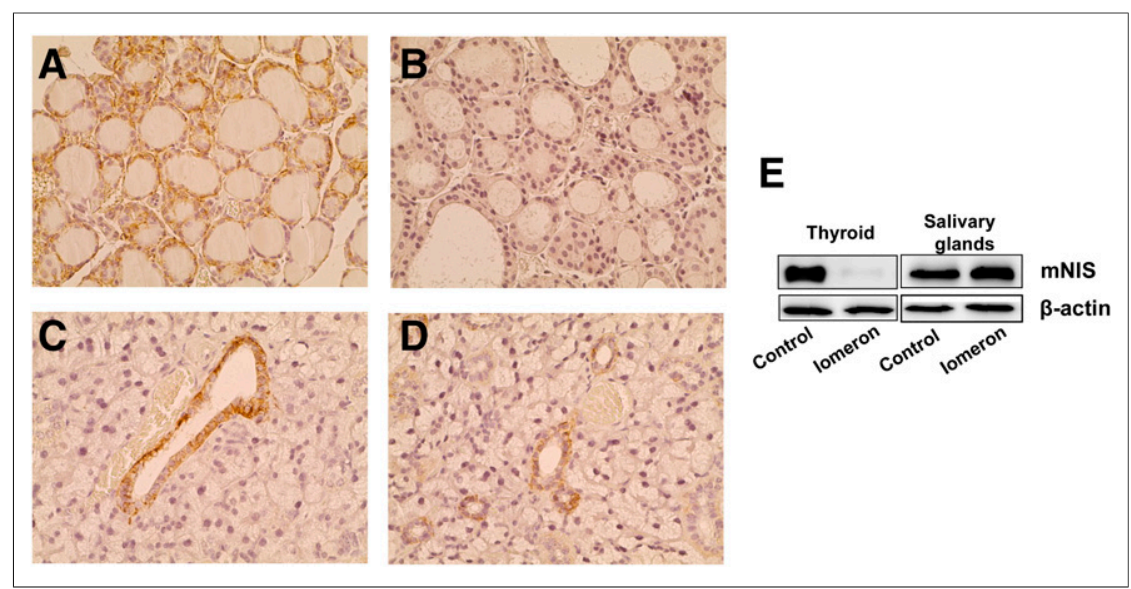

FIGURE 5. Analysis of NIS expression in thyroid and salivary glands in response to lomeron. Saline buffer ( $A$ and $C$ ) or lomeron (B and $D$ ) was administered intravenously. Four days later, animals were culled and NIS expression in thyroid (A and B) and salivary glands (C and D) was analyzed by immunohistochemistry ( $n=3$ per group). Thyroid and salivary glands were also processed for Western blot analysis of NIS and $\beta$-actin expression ( $n=2$ per group).

The mechanism by which ICM reduces iodide uptake by the thyroid involves a dramatic reduction in the expression of the NIS protein. Four days after ICM injection, the NIS protein was hardly

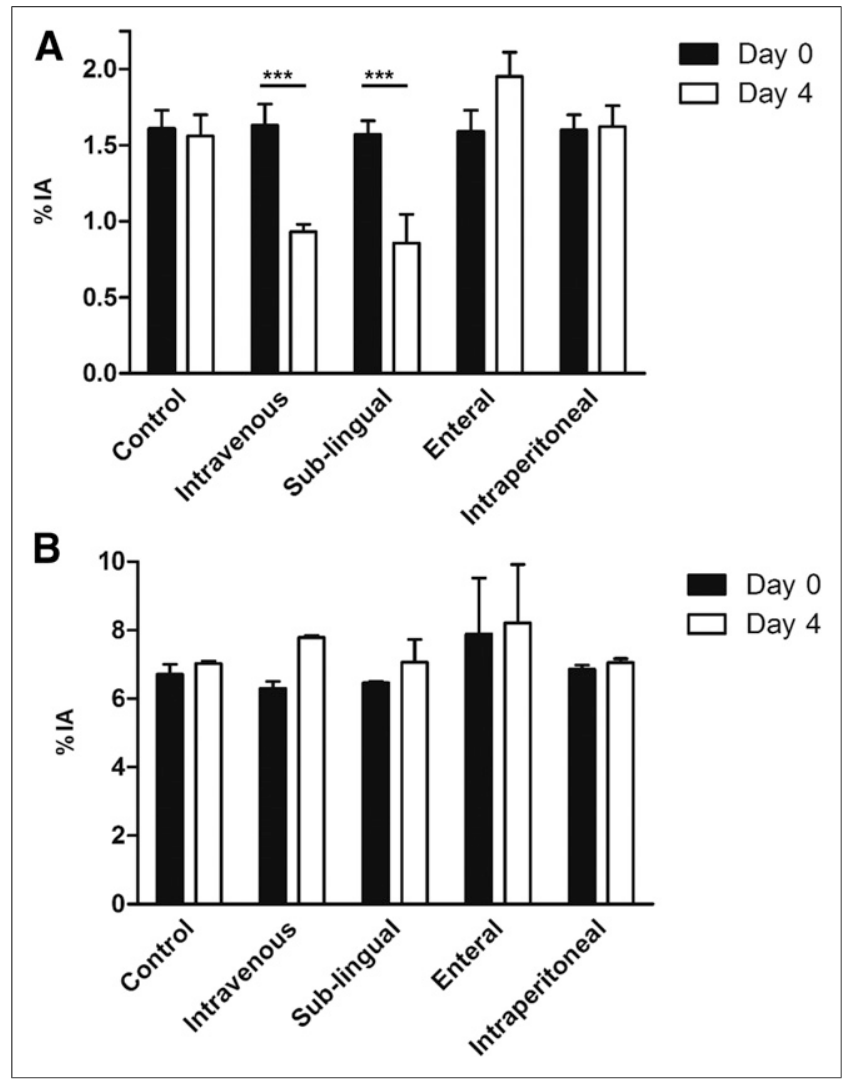

FIGURE 6. Evaluation of effect of different modes of administration of

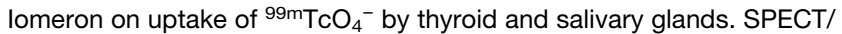

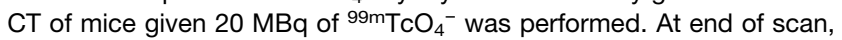
lomeron was administered intravenously, sublingually, enterally, and intraperitoneally. Four days later, animals were injected with $20 \mathrm{MBq}$ of ${ }^{99 \mathrm{~m}} \mathrm{TcO}_{4}{ }^{-}$and new scans were obtained. Data are percentage radiotracer taken up by thyroid $(A)$ and salivary glands $(B)(n=2$ per condition). ${ }^{\star \star \star} P<0.001 . \% \mathrm{IA}=$ percentage injected activity. detectable using immunohistochemistry. Western blot analysis confirmed this observation. As expected from the functional imaging data, NIS protein expression was unaffected in the salivary glands. To exert this effect, it is likely that ICM trigger an intracellular molecular mechanism that results in reduced NIS protein expression. ICM have been shown to trigger various intracellular signaling pathways in kidney cells (31-33), which could be involved in the effect observed on the thyroid. The molecular mechanisms involved in the thyroidspecific effect of ICM are currently under investigation in our laboratory.

Although effective and safe overall, the use of KI tablets to protect populations in the event of a nuclear incident is associated with some problematic issues. In cases of prolonged ${ }^{131}$ I exposure, the U.S. Food and Drug Administration recommends that KI tablets be ingested on a daily basis (34), with potential logistic and compliance problems. In this context, "one-shot" measures that could replace KI tablets or reduce the requirement for a stringent compliance to the daily intake of KI tablets would be welcome. Formulations based on ICM could provide this benefit. Given that the intravenous mode of administration is hardly relevant for an application in radioprotection, the sublingual delivery of ICM is efficient in mice and could be considered in humans. In addition, ICM could be chemically modified to be absorbed by the gut epithelium, leading the way to a compound administered orally. Furthermore, elucidation of the molecular mechanisms involved in the effects of ICM on the thyroid could provide a basis for the selection of new compounds that could be used in radioprotection.

\section{CONCLUSION}

One side effect of the use of ICM is alteration of iodide uptake by the thyroid. This effect is thought to be mediated by free iodide associated with or released from ICM. In the present report, we demonstrated that ICM induces thyroid stunning to a greater and longer-lasting degree than the free iodide found in ICM would explain. The effect is due to a specific and dramatic decrease in NIS expression in thyrocytes. These data cast serious doubt on the relevance and usefulness of the measurement of urinary iodide concentration to evaluate the delay between ICM administration and radioiodine therapy of patients with differentiated thyroid carcinoma. Finally, the ability of ICM to perturb iodide uptake in the thyroid on a relatively long-term basis could be exploited in radioprotection.

\section{DISCLOSURE}

This work was supported by INSERM, the French National Research Agency (ANR), and a grant from "Plan Cancer 20142019" (MTS201403). Equipment for this study was purchased through grants from "la Région Provence Alpes-Côte d'Azur." A patent on the utilization of ICM in radioprotection is currently being processed. The IRCAN Histology core facility is supported by the University of Nice Sophia-Antipolis and INSERM. No other potential conflict of interest relevant to this article was reported. 


\section{ACKNOWLEDGMENTS}

We thank the radiopharmaceutical team of the Centre Antoine Lacassagne (Nadine Sapin, Guy Martinico, Stéphane Espitallier, and Didier Alberato) for their help with radioisotope production and handling. We thank Colette Ricort for assistance in preparing the manuscript. We thank Catherine Pons in the IRCAN Histology core facility. We thank the IRCAN Animal Core Facility for providing access to their equipment.

\section{REFERENCES}

1. Grayson RR. Factors which influence the radioactive iodine thyroidal uptake test. Am J Med. 1960;28:397-415.

2. Rogers WR, Robbins LR. Iodipamide (cholografin) administration: its effect on the thyroid uptake of $\mathrm{I}^{131}$ and the serum precipitable iodine in euthyroid persons. N Engl J Med. 1955;253:424-425.

3. Slingerland DW. Effects of an organic iodine compound priodax on tests of thyroid function. J Clin Endocrinol Metab. 1957;17:82-93.

4. van der Molen AJ, Thomsen HS, Morcos SK. Effect of iodinated contrast media on thyroid function in adults. Eur Radiol. 2004;14:902-907.

5. Jaffiol C, Baldet L, Bada M, Vierne Y. The influence on thyroid function of two iodine-containing radiological contrast media. Br J Radiol. 1982;55:263-265.

6. Pacini F, Schlumberger M, Dralle H, Elisei R, Smit JW, Wiersinga W. European consensus for the management of patients with differentiated thyroid carcinoma of the follicular epithelium. Eur J Endocrinol. 2006;154:787-803.

7. Haugen BR, Alexander EK, Bible KC, et al. 2015 American Thyroid Association management guidelines for adult patients with thyroid nodules and differentiated thyroid cancer: The American Thyroid Association guidelines task force on thyroid nodules and differentiated thyroid cancer. Thyroid. 2016;26:1-133.

8. Luster M, Clarke SE, Dietlein M, et al. Guidelines for radioiodine therapy of differentiated thyroid cancer. Eur J Nucl Med Mol Imaging. 2008;35:1941-1959.

9. Laurie AJ, Lyon SG, Lasser EC. Contrast material iodides: potential effects on radioactive iodine thyroid uptake. J Nucl Med. 1992;33:237-238.

10. Padovani RP, Kasamatsu TS, Nakabashi CC, et al. One month is sufficient for urinary iodine to return to its baseline value after the use of water-soluble iodinated contrast agents in post-thyroidectomy patients requiring radioiodine therapy. Thyroid. 2012;22:926-930.

11. Lee SY, Chang DL, He X, Pearce EN, Braverman LE, Leung AM. Urinary iodine excretion and serum thyroid function in adults after iodinated contrast administration. Thyroid. 2015;25:471-477.

12. Talner LB, Coel MN, Lang JH. Salivary secretion of iodine after urography: further evidence for in vivo deiodination and salivary secretion of contrast media. Radiology. 1973;106:263-268.

13. Caillou B, Troalen F, Baudin E, et al. Na+/I- symporter distribution in human thyroid tissues: an immunohistochemical study. J Clin Endocrinol Metab. 1998; 83:4102-4106.

14. Peyrottes I, Navarro V, Ondo-Mendez A, et al. Immunoanalysis indicates that the sodium iodide symporter is not overexpressed in intracellular compartments in thyroid and breast cancers. Eur J Endocrinol. 2009;160:215-225.

15. Vayre L, Sabourin JC, Caillou B, Ducreux M, Schlumberger M, Bidart JM. Immunohistochemical analysis of $\mathrm{Na}+/ \mathrm{I}-$ symporter distribution in human extra-thyroidal tissues. Eur J Endocrinol. 1999;141:382-386.
16. Franken PR, Guglielmi J, Vanhove C, et al. Distribution and dynamics of ${ }^{99 \mathrm{~m}} \mathrm{Tc}$-pertechnetate uptake in the thyroid and other organs assessed by singlephoton emission computed tomography in living mice. Thyroid. 2010;20:519-526.

17. Perron B, Rodriguez AM, Leblanc G, Pourcher T. Cloning of the mouse sodium iodide symporter and its expression in the mammary gland and other tissues. J Endocrinol. 2001;170:185-196.

18. Richard-Fiardo P, Franken PR, Lamit A, et al. Normalisation to blood activity is required for the accurate quantification of $\mathrm{Na} / \mathrm{I}$ symporter ectopic expression by SPECT/CT in individual subjects. PLoS One. 2012;7:e34086.

19. Leoni SG, Kimura ET, Santisteban P, De la Vieja A. Regulation of thyroid oxidative state by thioredoxin reductase has a crucial role in thyroid responses to iodide excess. Mol Endocrinol. 2011;25:1924-1935.

20. Merron A, Baril P, Martin-Duque $\mathrm{P}$, et al. Assessment of the $\mathrm{Na} / \mathrm{I}$ symporter as a reporter gene to visualize oncolytic adenovirus propagation in peritoneal tumours. Eur J Nucl Med Mol Imaging. 2010;37:1377-1385.

21. Cambien B, Franken PR, Lamit A, et al. ${ }^{99} \mathrm{TcO}_{4}{ }^{-}$, auger-mediated thyroid stunning: dosimetric requirements and associated molecular events. PLoS One. 2014;9:e92729.

22. Loening AM, Gambhir SS. AMIDE: a free software tool for multimodality medical image analysis. Mol Imaging. 2003;2:131-137.

23. Richard-Fiardo P, Hervouet C, Marsault R, et al. Evaluation of tetrafunctional block copolymers as synthetic vectors for lung gene transfer. Biomaterials. 2015;45:10-17.

24. Zwarthoed C, Chatti K, Guglielmi J, et al. Single-photon emission computed tomography for preclinical assessment of thyroid radioiodide uptake following various combinations of preparative measures. Thyroid. 2016;26:1614-1622.

25. Lee SY, Rhee CM, Leung AM, Braverman LE, Brent GA, Pearce EN. A review: radiographic iodinated contrast media-induced thyroid dysfunction. $J$ Clin Endocrinol Metab. 2015;100:376-383.

26. Kornelius E, Chiou JY, Yang YS, Peng CH, Lai YR, Huang CN. Iodinated contrast media increased the risk of thyroid dysfunction: a 6-year retrospective cohort study. J Clin Endocrinol Metab. 2015;100:3372-3379.

27. Schaffhauser K, Hanscheid H, Rendl J, Grelle I, Reiners C. Intrathyroidal iodine concentration after application of non-ionic contrast media with and without prophylactic application of perchlorate [in German]. Nucl Med (Stuttg). 2005;44:143-148.

28. Zuckier LS, Dohan O, Li Y, Chang CJ, Carrasco N, Dadachova E. Kinetics of perrhenate uptake and comparative biodistribution of perrhenate, pertechnetate, and iodide by $\mathrm{NaI}$ symporter-expressing tissues in vivo. J Nucl Med. 2004;45:500-507.

29. Sohn SY, Choi JH, Kim NK, et al. The impact of iodinated contrast agent administered during preoperative computed tomography scan on body iodine pool in patients with differentiated thyroid cancer preparing for radioactive iodine treatment. Thyroid. 2014;24:872-877.

30. Mishra A, Pradhan PK, Gambhir S, Sabaretnam M, Gupta A, Babu S. Preoperative contrast-enhanced computerized tomography should not delay radioiodine ablation in differentiated thyroid carcinoma patients. J Surg Res. 2015;193:731-737.

31. Lee HC, Sheu SH, Yen HW, Lai WT, Chang JG. JNK/ATF2 pathway is involved in iodinated contrast media-induced apoptosis. Am J Nephrol. 2010;31:125-133.

32. Gong X, Celsi G, Carlsson K, Norgren S, Chen M. N-acetylcysteine amide protects renal proximal tubular epithelial cells against iohexol-induced apoptosis by blocking p38 MAPK and iNOS signaling. Am J Nephrol. 2010;31:178-188.

33. Andreucci M, Lucisano G, Faga T, et al. Differential activation of signaling pathways involved in cell death, survival and inflammation by radiocontrast media in human renal proximal tubular cells. Toxicol Sci. 2011;119:408-416.

34. Frequently asked questions on potassium iodide (KI). U.S. Food and Drug Administration website. http://www.fda.gov/Drugs/EmergencyPreparedness/ BioterrorismandDrugPreparedness/ucm072265.htm. Updated October 14, 2016. Accessed October 31, 2017. 